\title{
Changing the role of the Russian university teacher: The route to sustainable education
}

\author{
Nicholas Wise ${ }^{1}$, Marina Vidrevich $^{2, *}$, and Irina Pervukhina ${ }^{2}$ \\ ${ }^{1}$ Liverpool John Moores University, Liverpool, UK \\ ${ }^{2}$ Ural State University of Economics, 8 Marta/Narodnoy Voli St., 62/45, 620144 Ekaterinburg, Russia
}

\begin{abstract}
Nowadays, the changes in the university context confront educators with challenges and dilemmas, which make them seek new approaches to training graduates that will be employable in the national labour market. One of most essential issues is if faculty can meet the demands of the changing educational environment. Thus, in the present paper the authors aim to reflect on the content of teachers' training in the Russian HE; to identify the existing weaknesses, needs and emerging issues in teaching practices and to match them with the best EU teaching practices, as well as to work out some recommendation for developing a sustainable teachers' training model that targets to improve qualification of university teaching staff in educational methods and pedagogical approaches that are considered in the outcome-based and quality assurance context, which impart sustainable education to their students for better employability..
\end{abstract}

\section{Introduction}

Globalisation and the evolution of the knowledge-based economy have caused dramatic changes in the character and functions of higher education (HE) in most countries around the world. However, the impacts of globalisation on universities are not uniform even though similar business-like practices have been adopted to cope with competition in the global marketplace. The pressure for restructuring and reforming HE is mainly derived from growing expectations and demands of different stakeholders in society for achieving sustainable education.

HE in Russia has changed a lot in recent decades. Changes which were influenced by Russia co-signing the Bologna Declaration in 2003 coupled with the impact of information and communication technologies on various areas of knowledge. In the present circumstances, the changes in the university context confront educators with challenges and dilemmas, which make them seek qualification, knowledge and methodologies for teaching which enable faculty to meet new demands of HE, such as pedagogical knowledge, diversity and inclusion of students, the use of technology, teaching with research, active methodologies, peer and collaborative learning [1].

At the same time, according to country analysis from the 2019 edition of the Global Competitiveness Index 4.0 [2] the quality of education in Russia is not keeping up with the

\footnotetext{
${ }^{*}$ Corresponding author: mbv@usue.ru
} 
needs of a modern economy. Researchers [3, 4] recognize that the Russian higher education institutions (HEI) are experiencing demographic crisis that is caused by lack of qualified teaching staff; rapid ageing of academic staff; the reluctance of graduates to build their career as faculty members, hence the outflow of young teachers to other sectors of industry with higher income. There is an indication of the degree of HEI differentiation across the country by the level of teacher qualifications and quality of teaching.

In the institutional restructuring of $\mathrm{HE}$ which role do teachers and teacher training play? The emphasis on the teacher is highlighted by Vaillant and Marcelo [5] who emphasize the continuity of teachers' professional development as a process that encourages self-training. In our fast-paced, ever changing world, teacher learning never stops. As soon as a new skill or tool is mastered and implemented, a new piece of learning is available.

Teacher's professional competence is one of the main components that ensures the quality of provided educational services. Professional competence of a university teacher is an integral structure and ensures effective teaching performance [6]. Enhanced professional competence of university teachers is both the goal and the most important task of university management. Currently, this goal is attained through the system of in-house professional teachers' training which might have a variety of forms and methods. The need for reforming this system in Russian universities arises from the following terms and conditions:

- The content of teachers' training programs should meet the requirements of the Bologna educational system;

- The Federal State Educational Standards of secondary and higher professional education of the third generation (FSES 3+; FSES 3++) should be applied as they enforce significantly changed guidelines of the national educational system, i.e. a shift from pure knowledge to an ability to successfully solve professional tasks on the basis of acquired knowledge, skills, and experience.

- University academic staff should comply with the qualification standard [7] for the position held. If university teachers have no pedagogical background, they are obliged to undergo specific training.

The process of reforming the teachers' training model can be built on the European experience, which, at the same time, must take into account the Russian specifics and realities. It is extremely important that this transformation does not lead to the loss of the essential component, which might have an adverse effect: the system might stop working.

Consequently, it is important that the university teaching staff know how to use educational technologies as a resource of enhanced teaching and innovative learning, that they recognize that nowadays university learning involves aspects related to professional practice, skills and abilities that need to be developed and harmonized with the demands, values and attitudes of contemporary sustainable society [1].

\section{Problem statements}

Given the necessity of continuing professional development for HE teachers, the research of this paper presents the authors' perceptions of the Continuous Professional Development (CPD) model that aims to provide teachers' training for two groups of teaching staff: experienced members of the academic staff who lack professional pedagogical training and graduates who have completed their university course and aim to teach in their respective professional areas. 


\section{Research questions}

The following questions can be posed as research problem: What are the contributions, implications and impacts of continuing education for HE teaching from the perceptions of professionals from various fields of knowledge? What are the key principles underlying a sustainable CPD program that can contribute to developing university teacher competences?

\section{Purpose of the study}

In the search for answers to the problem that guides this study, we aim to reflect on the content of continuous education for teacher's professional development in the Russian HE; to identify the existing weaknesses, needs and emerging issues in teaching practices and to match them with the best EU teaching practices, as well as to work out some recommendation for developing a sustainable teachers' training model that targets to improve qualification of university teaching staff in educational methods and pedagogical approaches.

\section{Research methods}

The methodological framework is based on systematic approach, which includes general scientific methods (deduction, induction, generalisation, comparative analysis, etc.). We also adopt here an integrated research model based on an interactionist approach considering the mutual influence between the reform of the institutional asset of education (macro-level) and the teacher individual pedagogical approach to the teaching and learning process (micro-level).

\section{Results and discussion}

The analysis of teaching practices in most Russian universities shows that in most cases faculty still remain translators of knowledge, and expect their student to remember and translate the information received from the lecturer. A survey conducted at the Ural State University of Economics (Yekaterinburg) at the end of 2019 indicated that $82 \%$ of faculty physically read lectures, in the sense they say the words that are written. The situation is similar in other universities, especially in regions. Moreover, an essential component of faculty teaching and learning materials for a course or module is a compendium of lectures.

Monitoring of university teachers' performance [8] revealed that they undervalue the importance of teaching methodology, usage of pedagogical technologies, and lack the knowledge in student psychology. This attitude is fostered by the fact that the vast majority of faculty has not been trained to be teachers and often lack knowledge on teaching in HE.

Young educators, who join the academic staff of the university, are, as a rule, this university graduates, and thus lack pedagogical training as well. That is why, at the beginning of their teaching careers novice tutors experience considerable difficulties: copying the teaching models they were observing while students, they continue to play the outdated role of a teacher as a translator of knowledge. On the other hand, following recommendations of the FSES $3++$, universities should involve employers in the teaching process. However, employers also lack relevant pedagogical and / or psychological background and thus do not meet the requirements of the university teacher professional standard. Who, then, will teach students? 
The last "Common European Principles for Teacher Competences and Qualifications" [9] illustrate some new trends in teacher education and profession, which are inspired by discourses and major features of the knowledge society. In the document, the key competences teachers have to achieve are clustered under three macro-categories [9]: (1) work with others; (2) work with knowledge, technology and information; and (3) work with and in society.

According to University 20.35 (https://2035.university/en/), more specifically, in order to effectively contribute to professionalization, the XXI century teacher competence profiles should include such skills as attention management, empathy, creative approach to performing professional tasks, cooperation, communication, ability to search, evaluate and deploy learning materials; different domains of thinking (systemic, long-term, problemoriented, etc.); ability to work in interdisciplinary and intercultural teams; conflict resolution; lifelong learning. Most important, teachers are expected to instil in their student's motivation for developing autonomous learning patterns. This implies encouraging and teaching self directed learning skills (learning how to learn) and attitudes by establishing a teaching and learning setting that recognizes students' individual learning styles.

The system of university teacher training should be built around innovative pedagogy and methodology; assist educators in application and design of blended and advanced methods of delivering educational content [10]. The main areas of training academic staff are determined by the need to update the existing educational programs, which must meet the changing needs and expectations of society. Under the conditions of fierce competition, universities should offer interdisciplinary courses that satisfy the needs of future students, both in terms of content and quality of teaching $[6,11]$. In order to successfully deliver new training programs, universities need not only to form a cohort of young educators, but also to develop new skills for experienced teachers and offer, among other things, new approaches to improving their skills.

With the spread of the COVID-19 that resulted in extended school and university closures, Russia, like many countries around the world, is pursuing options to utilize remote learning to manage and cope with the crisis in education. The latter may cause not only loss of learning in the short-term, but also further loss in human capital and diminished economic opportunities in the long-term. With most of the students now at home, the pandemic is revealing disparities_in digitally-based distance learning. Many regional universities do not possess sufficient online learning facilities. Teachers also are struggling with the rapid transition to online learning, especially aged ones (they constitute over 40 per cent of university faculty). Their attempts to transfer teaching methods they are used to from a traditional classroom to online means fail.

Therefore, a modern teacher should be able to:

- apply an outcome-based approach to teaching and learning that might have a synergetic effect;

- employ interactive teaching techniques that target to achieve certain learning outcomes, and focus on dynamic interaction between students, as well between students and the teacher;

- apply personal approach in curriculum design.

The outcome-based approach to teachers' training should be implemented through the modular principle of constructing university educational course. This principle allows educators to update the content on a regular basis, respond adequately to changes in research and pedagogical context; introduce innovative teaching and learning techniques. The Teacher Training Program (TTP) can be implemented through a series of workshops that are designed to improve the teaching skills of both novice and experienced faculty and can covered learning strategies, teaching methods, testing, and evaluation of teaching skills. 
In our opinion, large universities are advisable to concentrate their CPD endeavours upon setting up a specialized training centre. The main objectives of the Centre are to create a comfortable learning environment for professional development of the teaching staff; to enhance teaching practice of postgraduate students; to introduce advanced teaching and pedagogical strategies and innovative teaching and learning techniques; and consequently, to enhance quality assurance.

The work of the Centre will be built around a set of active-learning instructional materials including a didactic manual and a module guide. The former gives an overview of the most important types of didactic teaching strategies and their genesis as well as presents possible subject-specific applications of these strategies. It also introduces the Centre teaching staff to the contemporary teaching practice and to the core systemic principles of the pedagogical framework. The Manual offers a comprehensive set of professional guidelines and teaching tools for teacher training providers and leaders and gives an opportunity to teachers to select from a range of contemporary teaching strategies in both online and face-to-face contexts, including empirical strategy, problem-solving strategy, modelling strategy or other ones, depending on the teaching objectives. A module guide presents a summary of developments in higher education curriculum design in recent decades. It draws on practical experience to suggest user-friendly guidance for writing modules, courses and programs based around learning outcomes.

\section{Conclusion}

Progress in the HE and in the educational system for sustainable development as a whole largely depends on the quality of the teacher, but this implies improving teachers' qualification levels, and providing them with economic support and a better social status. The above described approach to university teachers' training may ensure standardization of teaching and learning, convenience of training; bridge participants' differences, and exercise self-control.

The key outcomes of the teachers' training model should be knowledge of modern pedagogical practice and psychology; the acquisition of new approaches to curriculum design; the application of modern teaching and learning techniques. The use of innovative strategies and updated content will enable academic staff to respond to the changing learning environment, and impart sustainable education to their students for better employability. The teachers' training model can impact university teachers since it enables the acquisition of pedagogical knowledge, which helps to develop the ability of transposing theory into practice with greater confidence in the pedagogical action, showing a direct impact on professional performance.

\section{References}

1. J. de Lima Ferreira, G.R. Bertotti, 7, 1425 (2016)

2. K. Schwas, The Global Competitiveness Report 2019, World Economic Forum, Cologny (2019)

3. N.I. Hohlova, L.R. Rustamova, Vestnik BGU, 4 (34), 335 (2017)

4. Yu.S. Ezrokh, The Education and Science J, 7 (21), 9 (2019)

5. D. Vaillant, C. Marcelo, Teaching how to teach: the four steps of learning (2012)

6. L.V. Bol'shanina, e-Koncept, $\mathbf{S 8}$ (2016)

7. Professional standard "Teacher of professional training, professional education and additional professional education" (approved by the order of the Ministry of Labour 
and Social Protection of the Russian Federation, September 8, 2015 No 608n), http://www.fgosvo.ru/

8. S.D. Reznik, O.A. Vdovina, Moscow University Bulletin, Series 20, Teacher Education, 1, 67 (2017)

9. European Commission Education and Culture, Common European principles for teacher competences and qualification (2010), http://www.pef.uni-lj.si

10. C. Englund, A.D. Olofsson, L. Price, Higher Ed. Res. \& Development, 36, 73 (2017)

11. J.C.G. Bertolin, Creative Education, 6, 2410 (2015) 